DOI: 10.20472/IAC.2017.034.058

CHARLES WILD

University of Hertfordshire, United Kingdom

\title{
THE FLIP SIDE: A CASE STUDY EXAMINING HOW THE REFINED FLIPPED CLASSROOM ENHANCES BAME STUDENT PERFORMANCE
}

\begin{abstract}
:
Student cohorts within UK Higher Education (HE) institutions have becomes increasingly diverse over the past decade. This has presented the HE sector with a number of challenges, including the need to evaluate whether the delivery of degree programmes, traditionally targeted at a predominantly white student cohort, are fit-for-purpose when programme cohorts are becoming increasingly culturally diverse and white students account for only the second or third largest ethnic group. For example, in this case study, $75.7 \%$ of the student cohort is classed as Black, Asian or Minority Ethnic (BAME), with the largest ethnic group being Asian at 32.4\%.
\end{abstract}

The National Union of Students (NUS, 2009) observed that 'Black students are less likely to be satisfied with their educational experience and to attain first-class degrees in comparison to their White peers', going on to note that 'a simple explanation for the attainment and satisfaction gap of Black students does not exist'. Furthermore, Berry \& Loke (2011) note that differences between Black and White students centre on the "rate of retention / withdrawal and achievement". In addition, the National Union of Students (2009) reported that a significant minority of BME students viewed their teaching and learning environment negatively, often speaking of alienation, exclusion and feeling invisible to lecturers.

Whilst Pewewardy (2008) highlights the fact that BAME students differ in the ways they learn and communicate, Morgan (2010) suggests that such students only differ "from what a given culture considers appropriate or normal." Consequently, the author asserts it is time for HE institutions to re-evaluate the concept of 'appropriate or normal' to one based on BAME students rather than that of a predominantly white one. This case study examines the use of a refined flipped-classroom model across an entire undergraduate programme may prove the key to an increase in the rates of retention and progression of BAME students on undergraduate programmes.

This paper examines the use of a refined flipped-classroom model across an entire undergraduate programme which has resulted in a significant increase in the retention of BAME students. Pioneered by Bergmann and Sams, the traditional flipped-classroom allows students to review lectures at times and in locations that suit them. It also provides students with a library of information to refer back to, proving invaluable in the lead-up to assessments. In this regard, a significant improvement in the progression of Home/EU BAME students may be noted during the period 2013/14 to 2014/15.

\section{Keywords:}

Refined flipped classroom; BAME students; Student retention; Student progression

JEL Classification: 123,124 


\section{Introduction}

Morgan (2010) observes that one of the main reasons that BAME students are likely to encounter problems within the educational environment as compared to their White counterparts is the incomplete knowledge of minority students' learning and communication styles. This is reinforced by the work of Dunn and Dunn (1993) who note that students from a particular culture are likely to perform poorly academically and regard their educational experience negatively if the teaching styles they experience do not match the ways in which they communicate and learn.

To take a very basic example, "in Chinese cultures there is a high level of collectivism... and a preference for working together in groups to solve problems" and is due, at least in part, to the fact that issues are addressed in their broad context, considering "a host of factors that operate in relation to one another" (Nisbett 2003) as opposed to the traditional European approach which focuses on categorization and straightforward rules. Indeed, as Shih (1919) observes, "in the Confucian humancentered philosophy man cannot exist alone; all action must be in the form of interaction between man and man."

Alongside this, studies such as that carried out by Pang (2008), highlight the fact that the cultural norms of many Asian Pacific American students emphasise humility and modesty which, in turn, makes them more open to supporting one another in the learning process. Morgan (2010: 116) goes on to note that cultural norms mean that these students also tend to regard their lecturers as a respected figure whose knowledge should not be challenged and whose function within the classroom is to "transmit knowledge to students". As such, many Asian Pacific American students remain relatively quiet and avoid discussion out of respect and humility rather than due to the fact that they are either disengaged or experiencing difficulties with the concepts being discussed.

Banks (2006) observes that many Anglo-American students display a preference to work alone, rather than in a group or a collective learning environment and, as such, may be seen as being field-independent in their educational studies. A consequence of this is that they are more likely to be detached, goal oriented, competitive, analytical, and logical (Irvine and York 1995; Pewewardy 2008). They also find it easier "to break down a whole subject or topic and understand that its parts added together can re-form the whole" Morgan (2010: 116) and links with Nisbett's (2003) observation of European learning being centred on categorisation and straightforward rules. By contrast, Banks notes that to African American and Latino students tend to be field-dependent and have a preference to work together. Indeed, Aronson \& Gonzales (1988) found that African American and Latino students improved academically when cooperative learning methods of teaching are utilised.

Therefore, as minority students differ in the ways they learn and communicate from their White peers (Pewewardy 2008), everything from the curricula, through to the learning, teaching and assessment practices used on a course will impact significantly 
on student engagement, educational experiences and, ultimately, on outcomes (Crozier et al (2008). However, it is also important to bear in mind Morgan's (2010) observation that minority students only differ "from what a given culture considers appropriate or normal." Consequently, within the UK Higher Education sector, where the traditional norm has been based on the provision of education to a predominantly white middle-class student cohort, the concept of 'appropriate or normal' is in urgent need of being updated so as to reflect an era in which university student cohorts are increasingly diverse and dramatically different to those of even ten years ago. Such initiatives should include the incorporate of greater opportunities within a course for collective learning to take place, strategies whereby students are encouraged to challenge knowledge given to them during lectures or classroom activities, as well as supported to develop their critical reasoning skills. However, as Mountford-Zimdars et al (2015) quite rightly warn, there are potential dangers associated with 'targeted intervention' which, whilst intended to eliminate bias against specific demographies, may in reality create a 'self-fulfilling prophecy' by reinforcing stereotypes.

\section{Challenging educational norms}

The author suggests that it is the ability to strike this difficult balance which must be achieved if $\mathrm{HE}$ institutions are to effectively enhance the performance and retention of BAME students on degree programmes (Wild 2017b). An inclusive 'post-racial' approach which seeks to "avoid labelling people (acknowledging that notions of diversity should not be restricted to particular issues such as ethnicity, faith or immigration status" (Mountford-Zimdars et al 2015) and that treats every member of a student cohort equally, needs to be balanced by the recognition of individual variations within that cohort. In other words, providing all students with an equal opportunity to succeed is a very different notion to that of treating every student equally.

Therefore, whilst a lecturer may believe that they are avoiding discrimination against a specific group of students by treating everyone the same way, in reality this practice is, in itself, discriminatory (Banks 2006; Gollnick and Chinn 2009). For example, requiring all students to follow one style of teaching can, inadvertently, benefits the group or groups of students who are most comfortable with that approach (Morgan 2010: 117). It is the author's assertion that this includes the traditional lecture/seminar format used on many undergraduate law degree courses within the UK HE sector.

In this respect, Bennett (2007) observes that in order to bridge cultural gaps, they need to be supported to reflect upon their own teaching styles as well as to understand the learning styles of their students without making generalizations. Bennett goes on to note that many lecturers tend to replicate the style and approach they experienced whilst students themselves. In order to break this cycle, they need to be deliberately challenged to teach in another manner. However, this should not represent the abandonment of one approach in favour of another. Rather, as Morgan (2010) suggests, the ideal teaching strategy for a culturally diverse cohort is to use as 
many modes as possible. This ensures that where students are weak in certain skills due to cultural norms, the introduction of such skills gradually allows them to learn new ways of accomplishing tasks (Morgan 2010: 119). Similarly, for those students who feel more comfortable with group learning, it affords the opportunity for them to engage more readily with their educational experience than in an environment which does not cater for such learning styles.

For this reason, the author suggests that the use of a refined flipped classroom model, which incorporates both the Socratic Method of learning and teaching as well as opportunities for group learning, effectively improves the retention and performance of BAME students. The process of challenge and subsequent understanding through the use of deep questioning encourages many Chinese and Asian Pacific students to step outside cultural norms and to challenge, rather than automatically accept, a lecturer's knowledge (Morgan 2010), thereby enhancing their critical reasoning skills. Similarly, whilst group learning within workshops may enhance the academic performance of field dependent student through cooperative learning within the classroom, it also provides an opportunity for field independent students to develop new skills. Indeed, the ability to either engage with critical thinking or to work effectively as part of a team are two of the core transferable skills which all employers look for in university graduates.

A further benefit of this refined model, as noted by Berger and Wild (2016), is that it has the useful by-product of enhancing teaching standards. In order to support this approach, HE institutions, and their staff, must appreciate (i) how to deliver these sessions, (ii) what they are intended to achieve, and (iii) to be able to assess students consistently and objectively. This, in turn, should also mitigate against the interplay between macro, meso and micro level problems within HE institutions which, as Mountford-Zimdars et al suggest, contribute to the existence of the BAME attainment gap.

\section{The Flipped Classroom}

The flipped classroom approach to delivery of a module or programme inverts the traditional model of teaching via a lecture and subsequent learning by way of homework to that of emphasising active forms of face-to-face learning in the classroom accomplished through the delivery of course content outside of the lecture theatre (Mason, Shuman \& Cook 2013). Typically, the course content is delivered online through recorded lectures complemented by extended reading and other modes of content delivery (Bishop 2013).

Whilst the approach was pioneered by Bergmann and Sams in 2008 there have been other attempted pedagogical models which have sought to encourage active learning amongst student cohorts, including auto-tutorials, team learning, peer instruction, inquiry learning, Just-in-Time Teaching, blended classrooms, hybrid courses, and POGIL (process oriented guided inquiry learning) (Freeman Herreid \& Schiller 2013: 
65). The underlying theme for all of these approaches being that active learning is far more effective than the traditional passive instruction of students.

The flipped classroom has a number of advantages, perhaps none more so than the flexibility afforded as to when, where and how many times a student may view lectures (Fulton 2012; Berger \& Wild 2016). Additional benefits include the use of technology that is flexible, accessible and appropriate for the $21^{\text {st }}$ Century (Fulton 2012). In this regard, Freeman Herreid \& Schiller (2013: 62) observe that the use of online videos appeals to students "in this electronic age where videos in particular have found a special place in the heart of the 'Awesome Generation'." Online lectures may also be accessed effectively and efficiently via a range of devices including personal computers or even mobile devices (McGarr, 2009). Consequently, rather than a student listening to a face to face lecture on Company Law or International Commercial Law and subsequently trying to answer assigned homework questions outside of the classroom, students view lectures online and read material before coming to class. Once in the classroom they engage in active learning through the use of assigned questions, case studies or group problem scenarios (Wild, Weinstein \& Santora 2017).

By bringing these types of exercises into the classroom, it provides students to engage in group learning, which engages a number of BAME student groups who are 'field dependent'. It also provides lecturers with a more effective insight into student progress and difficulties, enabling them to address quickly any perceived difficulties or misconceptions (Bergman \& Sams 2012). As such, lectures are no longer the primary mode of instruction; they are simply used to support traditional face-to-face, in-class activities (Freeman Herreid \& Schiller 2013: 64). Finally, the fact that students work in the classroom, often in groups, is thought to reinforce their understanding of the course material through active and co-operative learning (Maarek \& Kay 2015: 1) with an online library of stored information to refer back to (Berger \& Wild 2016).

There has been extensive research into the effectiveness of the flipped classroom in terms of enhancing both student engagement and performance in subjects as diverse as mathematics (Moore et al, 2014) and multimedia studies (Enfield, 2013). Wang \& Lee (2015) note that a study conducted by the Yale Centre for Teaching and Learning and the University of Massachusetts Amherst, demonstrated that the flipped classroom led to significant improvements in student comprehension, "especially among female students, underrepresented minority students and students with lower grade point averages". They go on to note that the average examination performance of students "improved by about 12 percent for [those] in the flipped classes compared to those in standard classes." Several other studies have also reported improvements in exam scores and problem solving skills as a result of the adoption of the flipped classroom (Day \& Foley 2006; Berger \& Wild 2016).

As noted earlier, the flipped classroom transfers responsibility of learning the course content away from the lecturer and on to the students, developing their skills to learn on their own (Felder \& Brent 2003). However, as Freeman Herreid \& Schiller (2013: 
63) note, students who are new to this method may initially find this shift in dynamic difficult to accept as it requires them to undertake a considerable amount work at home, as opposed to first being introduced to the subject matter by the lecturer in class. Consequently, until they become attuned to the expectations of this approach to delivery, some students may come unprepared to participate in the active learning aspect of the programme undertaken in the classroom. However, Freeman Herreid \& Schiller (2013: 63) suggest that this may be addressed by requiring students to use information in class that can only be obtained from the online lecture or outside independent reading.

\section{The refined flipped classroom model}

The University of Hertfordshire adopted the flipped-classroom model across its undergraduate law programme in 2011 . The decision to replace the traditional lecture and seminar format with that of the flipped classroom was influenced by students, who commented on the fact that traditional face-to-face lectures were not providing them with the necessary tools to progress from understanding legal theory and case law through to a state of being comfortable with either evaluating or analysing the subject matter. In other words, students wanted a greater opportunity to develop their critical thinking skills.

The challenge centred on the traditional lecture frequently being used by lecturers, who are acutely aware of the time constraints of university modules, as a vehicle to cover material in the curriculum. The inadvertent result of this is that students are encouraged to absorb the theory before moving on to the next portion of knowledge to be covered in the lecture. This, in turn, encourages many students to fall into the trap of simply accepting the lecturers' views on the subject matter (Wild 2017a). In other words, the model that had developed within the traditional face to face lecture and seminar format overlooked the need to provide students with the opportunity to form their own views of the course content. This vital part of the learning process was either being lost or, at the very least, subdued by the lecturers' focus on schedules and timetables for delivery, subject knowledge content that students need to learn as well as ensuring that they complied with university expectations of defensible curriculum delivery.

However, without additional face-to-face input in the classroom, the traditional flipped classroom may face the risk of simply replicating the same shortcomings of traditional live lectures, resulting in students accepting their lecturer's views as qualitative instead of quantitative (Berger \& Wild 2016). In other words, without encouraging lecturers to reflect on their teaching styles and challenging them to teach in a different way, students may very well continue to be taught WHAT to think, rather than HOW to think. Consequently, during their final assessments, it is quite understandable for many students to simply replicate the taught course content as outlined by their 
lectures unless they have been afforded the opportunity to develop their critical reasoning skills.

As such, a third stage was introduced to the process; the Skills Based Lecture. The 'skill' to be developed, and to be applied within this aspect of the programme's classroom environment, is that of critical reasoning. As noted earlier, it is important that lecturers and their students resist the temptation to cover ground that has already been dealt with, or assumed to have been dealt with, in the online lectures or further reading assigned before class. It is also important to avoid using the time to work through example problem scenarios which is to be covered in greater depth within the workshop component of the course. Rather, in order to develop students' critical thinking, it is essential that lecturers are prepared to go 'off topic', to leave behind a tutorial plan or restrictive curriculum, and to embrace the fact that the answer is often less important that the logical reasoning or the process of critical thinking being developed by their students (Berger \& Wild 2017). In this regard, the author suggests that one of the most effective ways in which critical reasoning amongst students may be developed, and encouraged, is through adoption of the Socratic Method within these Skills Based Lectures.

The Socratic Method transcends subject matter as it seeks understanding through deep questioning; the questioner as the unknowing bystander. However, as Berger \& Wild (2017) observe, it can be extremely difficult to use in the classroom with any true success, especially within the Higher Education that is focused on specific educational learning outcomes, and in measuring a student's knowledge at pre-determined intervals via assessments.

As such, the three elements of the refined flipped classroom model are:

(i) online lectures which are viewed outside the classroom;

(ii) the skills based lectures which are delivered face-to-face in groups of 40-50 student; and

(iii) workshops which are delivered face-to-face in groups of 12-15 students.

Within this refined flipped classroom model, the online lecture is seen by both lecturers and students as an online library, the aim of which is to provide a body of knowledge accompanied by external reading sources that are intended to extend a student's knowledge base and to provide contrasting perspectives on the subject matter. The skills based lecture is then intended to provide a forum for debate and the critical analysis of the topic (Berger \& Wild 2016). The Skills Based Lecture then provides an opportunity for students to engage in a qualitative debate regarding the course content, facilitated by the lecturer. The closer this classroom environment can replicate the Socratic Method, the greater the opportunity for critical reasoning to be encouraged and developed amongst the student cohort. In essence, by delivering the Skills Based Lecture in this way, there will never be repetition of the online lecture content. More importantly, students will be encouraged to challenge and/or question 
the knowledge with which they have been provided and, as such, taught HOW to think, not WHAT to think.

Finally, the workshop element ensures that students lead the debate and seek to apply both the foundation knowledge and critical analysis points of the topic to complex decision making scenarios (Wild, Weinstein \& Santora 2017). The role of the lecturer is to keep students on-course to best practice. By delivering the programme in this way, students are encouraged to engage with all three unique parts of the course.

\section{Conclusions}

The refined flipped-classroom model was adopted across an entire undergraduate programme and, during this time, the School has noted a significant improvement in the achievement and progression of BAME students enrolled on the programme.

When the academic performance of Home / EU (as opposed to overseas) students was compared during the period 2013/14 through to 2014/15, the following pattern of student achievement was noted. This has been broken down according to the broad ethnic groupings used by the University and focuses on the overall percentage of students who did not progress through the degree programme:

\begin{tabular}{|l|l|l|}
\hline Ethnicity & $2013 / 14$ & $2014 / 15$ \\
\hline White & 10 & 8 \\
\hline Asian & 13 & 10 \\
\hline Black & 15 & 13 \\
\hline Chinese & 4 & 2 \\
\hline
\end{tabular}

Source: Own institutions data

There is clear improvement in the academic achievement of all BAME students during this period, with a marked and consistent reduction in the non-progression of Asian, Black and Chinese students when benchmarked against their White peers. It is also interesting to note that there has been the same $2 \%$ reduction in the non-progression of White students during this period.

The refined flipped-classroom enables students to review lectures on multiple occasions, at times and in locations that suit them. It also provides students with a library of information to refer back to, proving to be an invaluable resource in the leadup to examinations and assignments. It is suggested by the author that, at least in 
part, this contributes to the clear improvement in the achievement and progression of home / EU BAME students highlighted above.

It is also suggested that by bringing active learning into the classroom, through the use of assigned questions, case studies or group problem scenarios (Wild, Weinstein \& Santora 2017), students are provided with the opportunity to engage in group learning. As noted earlier, this learning style appeals to 'field-dependent' students, many of whom tend to fall within BAME student groups. The refined flipped classroom also provides lecturers with a more effective insight into student progress and difficulties, enabling them to address quickly any perceived difficulties or misconceptions (Bergman \& Sams 2012). Finally, the introduction of the Skills Based Lecture which aims to develop and encourage a student's critical reasoning is a core element of this approach. The author suggests that the adoption of the Socratic Method provides the opportunity for the lecturer to go 'off topic' and to embrace the fact that the answer is often less important than the process of critical thinking being developed by their students (Berger \& Wild 2017). It is also suggested that this approach has the added benefit of challenging a number of cultural norms within a safe and structured environment whereby students are encouraged to challenge the knowledge given to them during the online and further reading portions of the course.

\section{Reference}

Aronson, E. \& A Gonzalez (1988) "Desegregation, Jigsaw, and the Mexican-American Experience", in Eliminating Racism: Profiles in Controversy, ed P A Katz and D A Taylor, p301-314 New York: Plenum

Banks, J A (2006), Cultural Diversity and Education: Foundations, Curriculum, and Teaching. New York: Pearson Education

Bennett, C I (2007) Comprehensive Multicultural Education: Theory and Practice. New York: Pearson Education

Berger.D \& Wild.C, (2016), Refining the traditional flipped classroom model to optimise student performance on undergraduate degree programmes, Journal of Commonwealth Law and Legal Education, 11(1) pp50-70

Berger.D \& Wild.C, (2017) Nevermore: A case study examining how the Socratic Method may be used to enhance student engagement and reduce the 'attainment gap' of black and minority ethnic (BME) students, Higher Education Review

Bergmann J \& Sams A. (2012), Flip your classroom: reach every student in every class every day, International Society for Technology in Education

Bishop JL. (2013), A controlled study of the flipped classroom with numerical methods for engineers, PhD Dissertation. Logan, Utah: Utah State University

Crozier, G. and Reay, D. (2008) 'The Socio-Cultural and Learning Experiences of Working Class Students in HE' ESRC Full Research Report. Swindon: Economic and Social Research Council 
Day JA, Foley JD. (2006), Evaluating a web lecture intervention in a human-computer interaction course. IEEE transactions on education. 49(4) pp420-431

Dunn, R. \& K Dunn (1993), Teaching Secondary Students through Their Individual Learning Styles: Practical Approaches for Grades 7-12. Boston: Allyn \& Bacon

Enfield, J. (2013) 'Looking at the Impact of the Flipped Classroom Model of Instruction on Undergraduate Multimedia Students at CSUN' Tech Trends, 57(6), pp14-27

Felder RM, Brent R. (2003), Designing and teaching courses to satisfy the ABET engineering criteria. Journal of Engineering Education, 92(1) pp7-25

Freeman Herreid C \& Schiller NA, (2013) Case Studies and the Flipped Classroom, Journal of College Science Teaching, 42(5), pp62-66

Fulton, K. (2012). Upside down and inside out: Flip your classroom $m$ to improve student learning. Learning \& Leading with Technology, 39(8), pp12-17

Gollnick, D M , and P C Chinn (2009), Multicultural Education in a Pluralistic Society. upper Saddle River, $\mathrm{N} J$ : Pearson Prentice Hall

Irvine, J J , and D E York (1995) "Learning Styles and Culturally Diverse Students: A Literature Review " In Handbook of Research on Multicultural Education, ed J A Banks and C A M Banks, pp484497 New York: Macmillan

Maarek, J.I., \& Kay, B. (2015). Assessment of performance and student feedback in the flipped classroom. 122nd ASEE Annual Conference \& Exposition, Seattle, WA. June 14-17, 10.18260/p.23602, https://peer.asee.org/assessment-of-performance-and-student-feedback-inthe-flipped-classroom

Mason GS, Rutar Shuman T, Cook KE. (2013) Comparing the effectiveness of an inverted classroom to a traditional classroom in an upper-division engineering course. IEEE Transactions on Education. 56(4) pp430-435.

McGarr, O. (2009) A review of podcasting in higher education: Its influence on the traditional lecture, Australasian Journal of Educational Technology, 25, pp309-321

Moore, A. J., Gillett, M. R. and Steele, M. D. (2014). 'Fostering Student Engagement with the Flip', The Mathematics Teacher, 107(6), pp420-425

Morgan, H (2010), Improving Schooling for Cultural Minorities: The Right Teaching Styles Can Make a Big Difference', Educational Horizons, pp114-120

Mountford-Zimdards, A., Sabri, D., Moore, J., Sanders, J., Jones, S. and Higham, L. (2015) 'Causes of differences in student outcomes', Report to Higher Education Funding Council for England (HEFCE) by King's College London, ARC Network and The University of Manchester

Nisbett, R.E (2003) The Geography of Thought: How Asians and Westerners think differently - and why, Nicholas Brealey Publishing

Pang, V O 2008 "Educating the Whole Child: Implications for Teachers" In Classic Edition Sources: Multicultural Education, ed J Noel, 127-131 New York: McGraw-Hill 
Pewewardy, C (2008) "Learning Styles of American Indian/Alaska Native Students" In Classic Edition Sources: Multicultural Education, ed J Noel, pp116-121 New York: McGraw-Hill

Wang.V \& Lee.J (2015) Study shows flipped classrooms benefit female students, Yale Daily News, 2 October, http://yaledailynews.com/blog/2015/10/02/study-shows-flipped-classrooms-benefitfemale-students/

Wild.C, (2017a) Flip the Script: Using the refined flipped classroom model to reduce the Black, Asian, Minority Ethnic (BAME) attainment gap, 29th International Academic Conference (IISES), 5-8 April, Rome, Italy

Wild.C, (2017b) Flip it Around: The positive impact that the refined flipped classroom may have on reducing the Black Asian Minority Ethnic (BAME) attainment gap, ICBTS International Academic Multidisciplinary Research Conference, 4-5 May, Munich, Germany

Wild.C, Weinstein.S \& Santora.J, (2017), “Enhancing the development of Law Students' critical reasoning skills through the use of Complex Decision-Forcing case studies", European Conference on Education, 30 June - 2 July, Brighton, UK. 